\title{
Growth, structure, and performance of depth-graded W/Si multilayers for hard x-ray optics
}

Windt, D.L.; Christensen, Finn Erland; Craig, W.W.; Hailey, C.; Harrison, F.A.; Jimenez-Garate, M.; Kalyanaraman, R.; Mao, P.H.

Published in:

Journal of Applied Physics

Link to article, DOI:

$10.1063 / 1.373681$

Publication date:

2000

Document Version

Publisher's PDF, also known as Version of record

Link back to DTU Orbit

Citation (APA):

Windt, D. L., Christensen, F. E., Craig, W. W., Hailey, C., Harrison, F. A., Jimenez-Garate, M., Kalyanaraman, R., \& Mao, P. H. (2000). Growth, structure, and performance of depth-graded W/Si multilayers for hard x-ray optics. Journal of Applied Physics, 88(1), 460-470. https://doi.org/10.1063/1.373681

\section{General rights}

Copyright and moral rights for the publications made accessible in the public portal are retained by the authors and/or other copyright owners and it is a condition of accessing publications that users recognise and abide by the legal requirements associated with these rights.

- Users may download and print one copy of any publication from the public portal for the purpose of private study or research.

- You may not further distribute the material or use it for any profit-making activity or commercial gain

- You may freely distribute the URL identifying the publication in the public portal 


\title{
Growth, structure, and performance of depth-graded W/Si multilayers for hard x-ray optics
}

\author{
D. L. Windt ${ }^{a)}$ \\ Columbia Astrophysics Laboratory, 550 West 120th Street, New York, New York 10027 \\ F. E. Christensen \\ Danish Space Research Institute, Copenhagen, Denmark \\ W. W. Craig and C. Hailey \\ Columbia Astrophysics Laboratory, 550 West 120th Street, New York, New York 10027
}

F. A. Harrison

California Institute of Technology, Pasadena, California 91125

M. Jimenez-Garate

Columbia Astrophysics Laboratory, 550 West 120th Street, New York, New York 10027

R. Kalyanaraman

Oak Ridge National Labs, Oak Ridge, Tennessee 37831

P. H. Mao

California Institute of Technology, Pasadena, California 91125

(Received 21 January 2000; accepted for publication 24 March 2000)

\begin{abstract}
We describe the development of depth-graded W/Si multilayer films prepared by magnetron sputtering for use as broad-band reflective coatings for hard x-ray optics. We have used specular and nonspecular $\mathrm{x}$-ray reflectance analysis to characterize the interface imperfections in both periodic and depth-graded W/Si multilayer structures, and high-resolution transmission electron microscopy (TEM) and selected area electron diffraction (SAED) to characterize the interface structure and layer morphology as a function of depth in an optimized depth-graded multilayer. From x-ray analysis we find interface widths in the range $\sigma=0.275-0.35 \mathrm{~nm}$ for films deposited at low argon pressure (with a slight increase in interface width for multilayers having periods greater than $\sim 20$ $\mathrm{nm}$, possibly due to the transition from amorphous to polycrystalline metal layers identified by TEM and SAED), and somewhat larger interface widths (i.e., $\sigma=0.35-0.4 \mathrm{~nm}$ ) for structures grown at higher Ar pressures, higher background pressures, or with larger target-to-substrate distances. We find no variation in interface widths with magnetron power. Nonspecular x-ray reflectance analysis and TEM suggest that the dominant interface imperfection in these films is interfacial diffuseness; interfacial roughness is minimal $\left(\sigma_{r} \sim 0.175 \mathrm{~nm}\right)$ in structures prepared under optimal conditions, but can increase under conditions in which the beneficial effects of energetic bombardment during growth are compromised. X-ray reflectance analysis was also used to measure the variation in the W and Si deposition rates with bilayer thickness: we find that the W and Si layer thicknesses are nonlinear with the deposition times, and we discuss possible mechanisms responsible for this nonlinearity. Finally, hard x-ray reflectance measurements made with synchrotron radiation were used to quantify the performance of optimized depth-graded W/Si structures over the photon energy range from 18 to $212 \mathrm{keV}$. We find good agreement between the synchrotron measurements and calculations made using either $0.3 \mathrm{~nm}$ interface widths, or with a depth-graded distribution of interface widths in the range $\sigma=0.275-0.35 \mathrm{~nm}$ (as suggested by $8 \mathrm{keV}$ x-ray and TEM analyses) for a structure containing 150 bilayers, and designed for high reflectance over the range $20 \mathrm{keV}$ $<E<70 \mathrm{keV}$. We also find for this structure good agreement between reflectance measurements and calculations made for energies up to $170 \mathrm{keV}$, as well as for another graded W/Si structure containing 800 bilayers, designed for use above $100 \mathrm{keV}$, where the peak reflectance was measured at $E=212 \mathrm{keV}$ to be $R=76.5 \pm 4 \%$ at a graze angle of $\theta=0.08^{\circ}$. (C) 2000 American Institute of Physics. [S0021-8979(00)04013-5]
\end{abstract}

\section{INTRODUCTION}

Depth-graded multilayer structures developed in recent years for use as broad-band x-ray reflective coatings are now

${ }^{\text {a)} E l e c t r o n i c ~ m a i l: ~ w i n d t @ a s t r o . c o l u m b i a . e d u ~}$ finding application in instrumentation for synchrotron radiation, and in particular for high-energy astrophysics. Indeed, depth-graded multilayers are the enabling technology for a new generation of hard x-ray astronomical telescopes, including those being developed for the HEFT ${ }^{1}$ and In-Focus ${ }^{2}$ 
balloon instruments and the Astro- $\mathrm{G}$ and Constellation-X satellite instruments. ${ }^{3}$ These new telescopes, operating at photon energies greater than $20 \mathrm{keV}$, will provide an improvement in sensitivity by a factor of $\sim 1000$ or more over previous (nonfocusing) instruments, and will undoubtedly lead to a number of important astronomical discoveries.

In a depth-graded multilayer structure the layer thicknesses vary with depth into the film stack, such that each bilayer is effectively tuned to a different x-ray wavelength, in order to achieve broad-band reflectance. Depth-graded multilayer structures are particularly effective in the hard $\mathrm{X}$-ray region $(E>20 \mathrm{keV})$ where hundreds or even thousands of bilayers can be used, in principle, as a result of the low absorption and consequently high penetration depth in the film at these energies. However, the performance of such structures depends critically on the achievable level of interface perfection: deviations from atomically smooth and chemically abrupt interfaces, i.e., interfacial roughness and interfacial diffuseness, respectively, will reduce the reflection coefficients at the interfaces, thereby reducing the overall reflectance of the multilayer stack. Interface imperfections can result from a variety of material- and/or growthdependent mechanisms, including the formation of mixedcomposition amorphous interlayers by diffusion or by mixing due to energetic bombardment during growth, and roughness resulting from surface stress or from low adatom surface mobility. Promising material combinations found to have relatively small interface imperfections and suitable for use in depth-graded x-ray multilayers include $\mathrm{Pt} / \mathrm{C},{ }^{4} \mathrm{Cu} / \mathrm{Si}^{5}$ and $\mathrm{W} / \mathrm{Si} ;{ }^{6-8}$ depth-graded W/Si multilayers, which have already been found to have good performance up to $\sim 70 \mathrm{keV}$, are the subject of the work described here.

The structure and properties of periodic W/Si multilayers have been investigated previously. In particular, Shih and Stobbs ${ }^{9}$ used Fresnel contrast electron microscopy to estimate that the interface widths were of order $1.2 \mathrm{~nm}$ in a sputtered W/Si multilayer having a period of $2.3 \mathrm{~nm} .{ }^{10}$ Hasan et al., ${ }^{11}$ using both $\mathrm{x}$-ray reflectance and energy dispersive spectroscopy, found evidence for significant resputtering of Si during $\mathrm{W}$ deposition (but no evidence for re-sputtering of $\mathrm{W}$ during $\mathrm{Si}$ deposition) in periodic $\mathrm{W} / \mathrm{Si}$ multilayers having a range of layer thicknesses, and prepared by magnetron sputtering under various deposition conditions (i.e., magnetron power, substrate temperature, etc.). They attribute re-sputtering and the formation of amorphous $\mathrm{W}-\mathrm{Si}$ interlayers to energetic bombardment during growth: their data are consistent with a two-stage process in which atoms from the most recently deposited Si layer are first transported through the growing $\mathrm{W}$ layer to the instantaneous film surface, and are then removed by collisions with energetic atoms (i.e., W adatoms, Ar ions, and especially neutral Ar atoms reflected from the $\mathrm{W}$ target) striking the surface. They suggest that $\mathrm{Si}$ can continue to be removed as long as $\mathrm{W}$ is being deposited, but the rate of removal decreases as the distance which the Si atoms must travel through the $\mathrm{W}$ layer to the surface increases, i.e., $\mathrm{Si}$ is removed effectively only for $\mathrm{W}$ layer thickness less than $\sim 1.0-1.5 \mathrm{~nm}$. A number of other structural and stability studies of periodic W/Si multilayers have been reported as well; ${ }^{12-20}$ of particular interest here are the small interface widths $(\sigma \sim 0.3 \mathrm{~nm})$ determined from $\mathrm{x}$-ray scattering measurements in 1.5-nm-period multilayers reported by Vidal and Marfaing, ${ }^{14}$ and in periodic multilayers of various periods reported by Salditt et al. ${ }^{19,20}$

In this work we have used specular and nonspecular $\mathrm{X}$-ray reflectance analysis to characterize the interface imperfections in both periodic and depth-graded W/Si multilayer structures. We have also used high-resolution transmission electron microscopy (TEM) and selected area electron diffraction (SAED) to characterize the structure and morphology as a function of depth in an optimized depth-graded multilayer, and we report on the high-energy $\mathrm{x}$-ray reflectance of depth-graded W/Si structures measured using synchrotron radiation over the photon energy range 18-212 $\mathrm{keV}$. The deposition and characterization techniques are described in Sec. II, while our experimental results are presented in Sec. III. We interpret these results in Sec. IV, and conclude in Sec. V with a summary of our findings and their significance, particularly with regard to the development of hard x-ray telescopes for high-energy astrophysics.

\section{EXPERIMENTAL AND DATA ANALYSIS TECHNIQUES}

Multilayer films were grown on polished, 100 - $\mu \mathrm{m}$-thick, 76-mm-diam $\mathrm{Si}(100)$ wafers by dc magnetron sputtering in argon of $99.998 \%$ purity using a deposition system that has been described previously. ${ }^{21}$ Films for high-energy synchrotron reflectance measurements were deposited (in the same system) onto superpolished, 1-cm-thick, 76-mm-diam $\mathrm{Si}(100)$ substrates (supplied by General Optics ${ }^{22}$ ). The individual $\mathrm{W}$ and Si layer thicknesses in periodic and depthgraded multilayers are adjusted by varying the computercontrolled rotational velocity of the substrate platen, which faces downward, as it rotates over the two $50-\mathrm{cm}-$ long $\times 9-\mathrm{cm}$-wide planar magnetrons (using targets of $99.95 \%$ purity $\mathrm{W}$ and $99.9 \%$ purity $\mathrm{Si}$ ) that are mounted along the diagonal of the square vacuum chamber and which face upward. The distance from the target to the substrate surface is adjustable, and was set in the range $7.5-11.5 \mathrm{~cm}$, as discussed in Sec. III. The deposition times required to produce specific layer thicknesses were determined from detailed rate calibrations, also discussed in Sec. III. The substrate temperature was neither measured nor controlled during deposition.

The argon pressure was controlled during deposition using a closed-loop feedback system incorporating a mass-flow controller and a capacitance manometer; except where otherwise noted, the cryopumped vacuum system reached a background pressure of the order of $5.0 \times 10^{-7}$ Torr prior to deposition, and the argon pressure was fixed during deposition at $1.50 \pm 0.01 \mathrm{~m}$ Torr. The power applied to each magnetron was held constant during deposition, and we have investigated multilayer films deposited at various power settings as discussed below.

Samples for electron microscopy were prepared by ion milling at liquid $\mathrm{N}_{2}$ temperature to prevent any beam heating which might result in re-crystallization and/or re-growth of any amorphous or fine grained polycrystalline layers in the 
film. Ion milling was done using a Gatan Duo ion mill with $5 \mathrm{keV}$ Ar atoms at a total beam current of $1 \mu \mathrm{A}$ and a sputtering angle of $15^{\circ}$. Preferential milling at an angle of $30^{\circ}$ on either side of the glue line (M-bond 610 epoxy, cured for $24 \mathrm{~h}$ at room temperature) was performed by slowing the rotation of the specimen to $2 \mathrm{rpm}$, compared to the $10 \mathrm{rpm}$ used outside this region. Final cleaning of the samples was done using $2.5 \mathrm{keV} \mathrm{Ar}$ (total current $\sim 1 \mu \mathrm{A}$ ).

TEM and SAED measurements were made using a JEOL-4000 high-resolution transmission electron microscope operating at $400 \mathrm{keV}$; this instrument has a point-topoint resolution of $0.16 \mathrm{~nm}$. Large area cross-sectional images of a depth-graded multilayer film were obtained under medium magnification $(\sim 100 \mathrm{k} \times)$, while through focus images on either side of Scherzer defocus $(-20 \mathrm{~nm})$, as well as SAED data, were acquired at high resolution.

Specular and nonspecular x-ray reflectance measurements were made using a four-circle diffractometer with a rotating anode $\mathrm{Cu}$ x-ray source and a pyrolytic graphite monochromator tuned to the $\mathrm{Cu} K \alpha$ line at $8.04 \mathrm{keV}$ ( $\lambda$ $=0.154 \mathrm{~nm}$ ). The angular resolution of the diffractometer was $\sim 0.02^{\circ}$. Fits to the $\mathrm{x}$-ray data, performed with the IMD software package, ${ }^{23}$ were used to determine layer thicknesses and interface parameters.

Specular reflectance measurements were made in $\theta-2 \theta$ geometry over the range from $0<\theta<8^{\circ}$. The measured reflectance data are compared with a calculation made using an algorithm based on recursive application of the Fresnel equations. The modified Fresnel coefficient formalism ${ }^{24}$ is used to account for the effects of interface imperfections, and both the reflection and transmission coefficients were modified at each interface. The effects of interfacial roughness and diffuseness are indistinguishable by specular reflectance measurements, and so the interface can be characterized simply in terms of an interface profile function parameterized by the interface width $\sigma$. Thus the Fresnel reflection $\left(r_{i j}\right)$ and transmission $\left(t_{i j}\right)$ coefficients at the interface between the $i$ th and $j$ th layers are modified according to the formulas first derived by Nevot and Croce, ${ }^{25}$

$$
r_{i j}^{\prime}=r_{i j} \frac{\widetilde{w}\left(q_{z, i}+q_{z, j}\right)}{\widetilde{w}\left(q_{z, i}-q_{z, j}\right)},
$$

and

$$
t_{i j}^{\prime}=t_{i j} \frac{1}{\widetilde{w}\left(q_{z, i}-q_{z, j}\right)},
$$

where

$$
q_{z, i}=\frac{2 \pi}{\lambda} \cos \theta_{i}
$$

$\lambda$ is the photon wavelength, $\theta_{i}$ is the propagation angle is layer $i$ (N.B., $q_{z, i}$ is the component of the momentum transfer vector along the substrate normal in layer $i$ ) and $\widetilde{w}$ is the Fourier transform of the derivative (along the $\hat{z}$ direction) of the interface profile function. ${ }^{26}$ Several interface profile functions were investigated, including the exponential, linear, sinusoidal, step, and error-function profiles described in

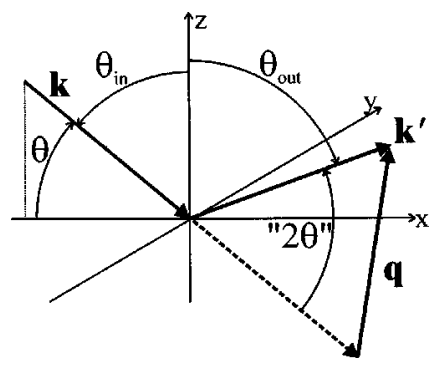

FIG. 1. Diagram illustrating the scattering angles for nonspecular x-ray reflectance measurements. The incident and scattered photons have momentum $\mathbf{k}$ and $\mathbf{k}^{\prime}$, respectively.

Refs. 24 and 26. Analysis of the specular reflectance data was used to determine the interface widths $\sigma_{i}$ as well as the individual $\mathrm{W}$ and $\mathrm{Si}$ layer thicknesses.

Nonspecular x-ray reflectance analysis can be used to distinguish between interfacial roughness and interfacial diffuseness, since interfacial roughness results in increased nonspecular scattering, whereas interfacial diffuseness does not. Nonspecular measurements performed here were made in "rocking scan" geometry, i.e., the sample is rotated and the detector fixed, so that the incidence angle $(\theta)$ is varied while the detector angle $(2 \theta)$ is constant. The measured data were compared with calculations of the nonspecular reflected intensity made using the distorted-wave born approximation (DWBA) formalism, ${ }^{27-30}$ computed as a function of $q_{\|}$, the component of the momentum transfer vector in the plane of the film:

$$
\begin{aligned}
q_{\|} & =\sqrt{q_{x}^{2}+q_{y}^{2}} \\
& =\frac{2 \pi}{\lambda} \sqrt{\sin ^{2} \theta_{\text {out }}+\sin ^{2} \theta_{\text {in }}-2 \sin \theta_{\text {out }} \sin \theta_{\text {in }}},
\end{aligned}
$$

where $\theta=\pi / 2-\theta_{\text {in }}$, and $2 \theta=\pi-\theta_{\text {in }}-\theta_{\text {out }}$ (see Fig. 1). We assume that each interface in the multilayer stack can be described by a power-spectral-density (PSD) function $s\left(q_{\|}\right)$ parameterized by an interfacial roughness $\sigma_{r}$, an in-plane correlation length $\xi_{\|}$, and a jaggedness parameter $H$, and that roughness correlations between two interfaces $i$ and $j$ can be described by a vertical correlation function $c_{j i}$ of the form ${ }^{30}$

$$
c_{j i}^{\perp}=\exp \left(-\sum_{n=j_{<}}^{j j_{>}^{-1}} z_{n} / \xi_{\perp}\right),
$$

where $\xi_{\perp}$ is the vertical correlation length, $z_{n}$ is the thickness of layer $n$, and $j_{<}=\min (j, i)$. Following de Boer, ${ }^{31}$ the PSD of the $j$ th interface is thus given by

$$
s_{j}\left(q_{\|}\right)=\exp \left(-z_{j} \xi_{\perp}\right) \frac{4 \pi H_{j} \sigma_{r, j}^{2} \xi_{\|, j}^{2}}{\left(1+\left|q_{\|, j}\right|^{2} \xi_{\|, j}^{2}\right)^{1+H_{j}}} .
$$

The Fresnel reflection and transmission coefficients, which are used to compute the electric field intensities needed for the DWBA, were modified (as in the case of the specular reflectance computations described above) assuming an interfacial diffuseness $\sigma_{d}$; the total interface width $\sigma$ (i.e., the interface width determined from specular reflectance analysis) is related to the interfacial roughness $\sigma_{r}$ and 


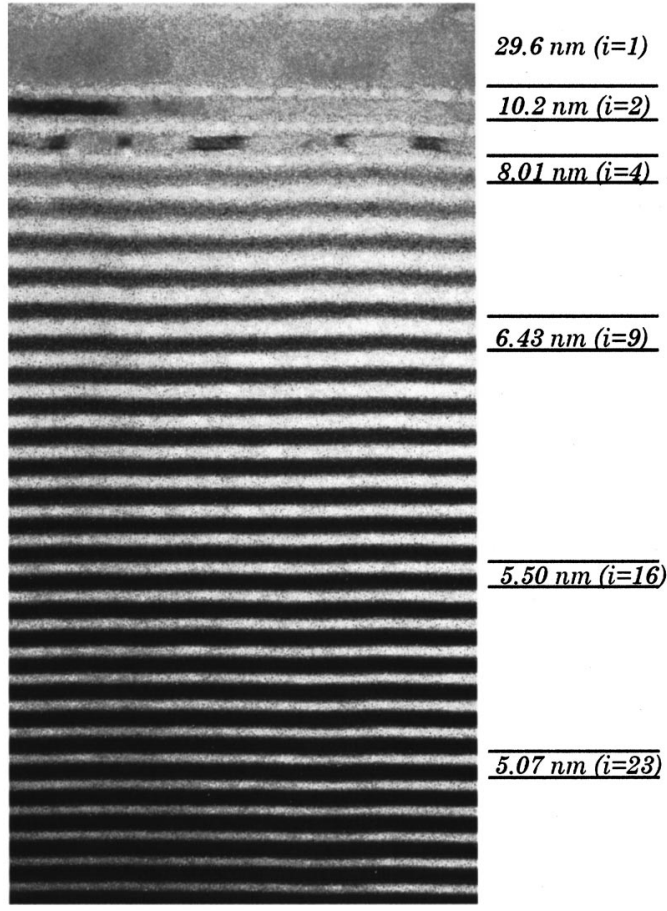

FIG. 2. Cross-sectional transmission electron micrograph of the top portion (i.e., the top $\sim 28$ bilayers) of a depth-graded W/Si multilayer structure. Selected bilayer indices and thicknesses [as per Eq. (7)] are indicated. The $\mathrm{W}$ (dark bands) and Si (light bands) layers are separated by thin amorphous $\mathrm{W}-\mathrm{Si}$ interlayers (gray bands). Note that the topmost Si layer is not completely visible in this image.

interfacial diffuseness $\sigma_{d}$ by $\sigma=\sqrt{\sigma_{r}^{2}+\sigma_{d}^{2}}$. Rocking-scan measurements were thus used to estimate the parameters $\sigma_{d}$, $\sigma_{r}, \xi_{\|}, H$, and $\xi_{\perp}$.

High-energy reflectance measurements were made on selected depth-graded multilayer samples at beamlines BM5 and ID $15 \mathrm{~A}$ at the European Synchrotron Radiation Facility (ESRF). A detuned double-reflection Si monochromator in reflection geometry was used over the range $18-54 \mathrm{keV}$ at bend-magnet beamline BM5, while higher energy measurements $(65-212 \mathrm{keV})$ made using the insertion device beamline ID 15A utilized a double-reflection Si (311) monochromator in the Laue geometry. Reflectance measurements were made in the $\theta-2 \theta$ geometry, using PIN diodes for both detector and monitor signals. The spectral resolution for all measurements was of the order of $\Delta E / E=10^{-4}$, while the angular resolution was of the order of $0.003^{\circ}$. The measured reflectance data were compared with calculations made using IMD, as described above.

\section{RESULTS}

Shown in Fig. 2 is a cross-sectional TEM image showing a portion (near the top) of a depth-graded W/Si multilayer containing 150 bilayers, with bilayer thicknesses in the range $d=3.33-29.6 \mathrm{~nm}$. This film is designed to have high reflectance up to the W $K$ edge near $E=70 \mathrm{keV}$ at grazing incidence angles near $\theta=0.095^{\circ}$, as required for a portion of the mirrors used in the HEFT telescope: ${ }^{32}$ the bilayer thickness distribution for this film is given by
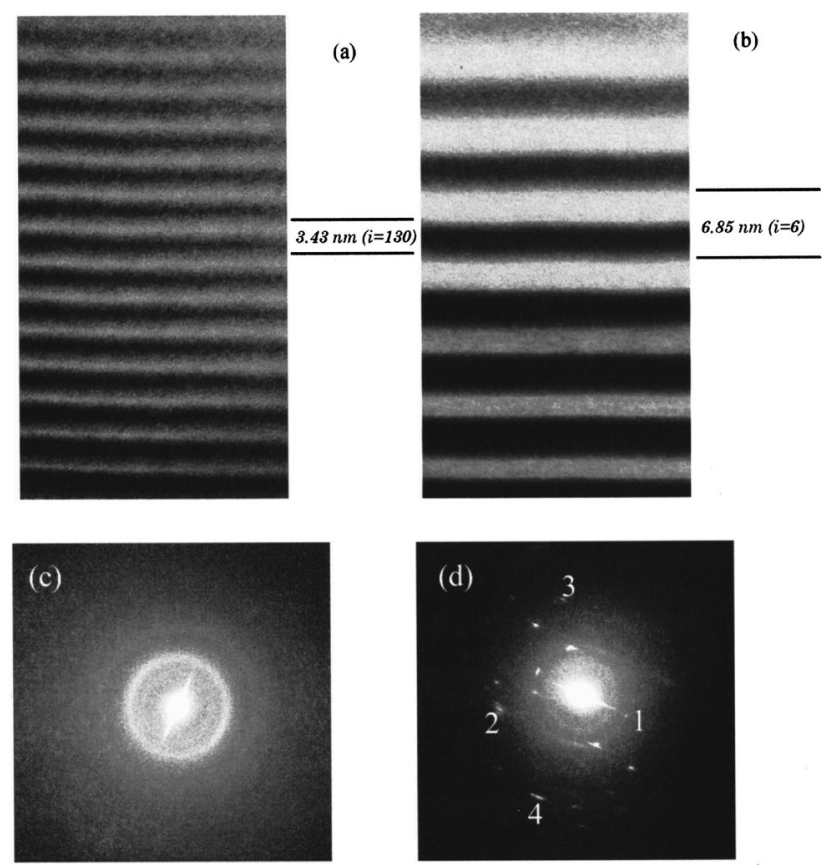

FIG. 3. High resolution TEM images of bilayers near the bottom (a) and top (b) of the structure shown in Fig. 2. SAED images obtained near the bottom (c) and top (d) of the same structure. The $\mathrm{W}$ diffraction peaks labeled $(1,2,3,4)$ in (d) correspond to lattice spacings $d=(0.221,0.129$, $0.113,0.099) \mathrm{nm}$, and Miller indices $(h k l)=[(110),(211),(220),(310)]$.

$$
d_{i}=\frac{10.27}{(i-0.991)^{0.225}}, \quad i=1, \ldots, 150,
$$

where $d_{i}$ is the thickness (in nm) of the $i$ th bilayer, with the topmost bilayer corresponding to $i=1 .{ }^{33}$

As can be seen from Fig. 2, the Si layers (light bands) are amorphous, as are the $\mathrm{W}$ layers (dark bands) in all but the top three bilayers $(d>8.8 \mathrm{~nm})$ where lattice fringes from individual $\mathrm{W}$ crystallites are visible. The $\mathrm{Si}$ and $\mathrm{W}$ layers are separated by relatively thin amorphous interlayers, presumably of mixed $\mathrm{W}-\mathrm{Si}$ composition (gray bands), which are easier to see in the high-resolution images (obtained at Scherzer defocus) of layers near the bottom and the top of the same multilayer film, having bilayer thicknesses of approximately $d \sim 3.4$ and $\sim 6.9 \mathrm{~nm}$, shown in Figs. 3(a) and 3 (b), respectively. A slight asymmetry in the W-on-Si vs $\mathrm{Si}$-on-W interlayers is visible in these images (in accord with the results obtained with periodic W/Si multilayers reported by Petford-Long et al.,$^{12}$ and by Salditt et al. ${ }^{19}$ ) as is a small increase in the interlayer widths with increasing bilayer thickness: by observing the image contrast in these TEM images we estimate, for example, interlayer widths $d_{\mathrm{W}-\text { on-Si }}$ $=0.83 \mathrm{~nm}$ and $d_{\text {Si-on-W }}=0.58 \mathrm{~nm}$ for the layers having $d$ $=3.43 \mathrm{~nm}$, and $d_{\mathrm{W} \text {-on-Si }}=1.08 \mathrm{~nm}$ and $d_{\mathrm{Si-on- \textrm {W }}}=0.63 \mathrm{~nm}$ for the layers having $d=6.86 \mathrm{~nm}$, somewhat smaller values than those reported by Shih and Stobbs ${ }^{9}$ and by Petford-Long et $a{ }^{12}$

SAED images obtained near the bottom and topmost layers of the multilayer stack are shown in Figs. 3(c) and 3(d). Diffraction spots marked in Fig. 3(d) correspond to $\alpha$-phase cubic tungsten, with lattice parameter $a \sim 0.315 \mathrm{~nm}$ and space group $\operatorname{Im} 3 \mathrm{~m}$. In contrast, the SAED image obtained 


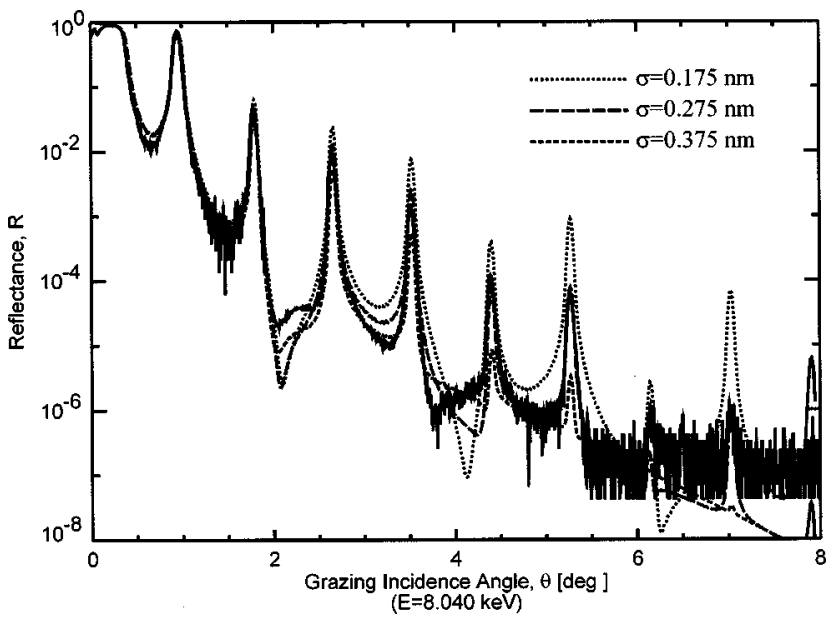

FIG. 4. Specular x-ray $(E=8.04 \mathrm{keV})$ reflectance of a periodic $\mathrm{W} / \mathrm{Si}$ multilayer containing 20 bilayers. Calculations made using various interface widths are indicated.

near the bottom of the film [Fig. 3(c)] shows only a diffuse ring pattern; the average radius of each ring is close to that of cubic tungsten. Although we cannot exclude the possibility of extremely fine-grained material, this result suggests that the $\mathrm{W}$ layers are amorphous in these thinner layers, which is unexpected in view of the metallic nature of W. However, a possible explanation can be that the "pure" W layers [excluding the thickest $\mathrm{W}$ layers near the film surface which show well-defined diffraction spots as shown in Fig. 3(d)] are actually composed of some amorphous $\mathrm{W}_{x} \mathrm{Si}_{y}$ phase that forms as a result of Si diffusion.

Shown in Fig. 4 is the grazing incidence x-ray reflectance measured for a periodic W/Si multilayer film containing 20 bilayers. This particular film was deposited at an argon pressure $P_{\mathrm{Ar}}=1.5 \mathrm{mTorr}$, and with a target-to-substrate distance $D=7.5 \mathrm{~cm}$.

We have attempted to fit the experimental reflectance data (for the sample shown in Fig. 4 as well as many others) assuming a variety of models, including layers composed either of pure amorphous $\mathrm{Si}$ and pure $\mathrm{W}$, or of $\mathrm{Si}$ and $\mathrm{W}_{x} \mathrm{Si}_{y}$, with either symmetric or asymmetric W-on-Si and Si-on-W widths (as suggested by the TEM results) using the modified Fresnel coefficient approach, trying various combinations of each of the interface profile functions mentioned above, as well as a model in which the amorphous $\mathrm{W}-\mathrm{Si}$ interlayers are treated as separate layers (with and without nonzero interface widths). In spite of these various attempts to reconcile the TEM and $\mathrm{x}$-ray reflectance data, we find that the best match between measurement and calculation is obtained with a model that includes layers composed of pure $\mathrm{W}$ and $\mathrm{Si}$, with interface imperfections described by the error-function interface profile [in which case the function $\widetilde{w}$ in Eqs. (1) and (2) described above is given by $\left.\widetilde{w}\left(q_{z, i}\right)=\exp \left(-\sigma_{i}^{2} q_{z, i}^{2} / 2\right)\right]$ using symmetric W-on-Si and Si-on-W interface widths. Using this model, we can adjust the individual $\mathrm{W}$ and $\mathrm{Si}$ layer thicknesses in order to accurately match the relative Bragg peak intensities; however if asymmetric interface widths are used, then the Bragg peak intensities tend to only decrease monotonically with increasing graze angle. Other interface profile functions (e.g., the exponential function) can result in somewhat larger interface widths, although they produce no significant improvement in the fit. Likewise, modeling the $\mathrm{W}-\mathrm{Si}$ interlayers as separate layers only results in greater computational costs while providing no clear benefit with regard to reproducing the measured reflectance, and the interlayer thicknesses that give the best match between measurement and calculation in this case are still much smaller than those observed by TEM. We do find a substantial improvement by including a $\mathrm{SiO}_{2}$ overlayer, however, particularly at graze angles just greater than the critical angle for total external reflection, where the reflectance is most sensitive to the condition of the film surface: assuming that the top layer of $\mathrm{Si}$ is fully oxidized (resulting from exposure to air), and with approximately equal densities for amorphous $\mathrm{Si}$ and amorphous $\mathrm{SiO}_{2}$ (i.e., $\rho_{\mathrm{Si}} \sim \rho_{a-\mathrm{SiO}_{2}} \sim 2.2 \mathrm{~g} / \mathrm{cm}^{3}$ ), the thickness of the amorphous $\mathrm{SiO}_{2}$ layer is related to the amorphous $\mathrm{Si}$ layer thickness by $d_{a-\mathrm{SiO}_{2}}=1.57 d_{\mathrm{Si}}$.

We thus show for comparison in Fig. 4 calculated reflectance curves computed with identical W-on-Si and Si-on-W interface widths $\sigma=0.175,0.275$, and $0.375 \mathrm{~nm}$, assuming an error-function interface profile, and an amorphous $\mathrm{SiO}_{2}$ overlayer having a thickness $d_{a-\mathrm{SiO}_{2}}=4.56 \mathrm{~nm}$. (The $\mathrm{SiO}_{2}$ surface roughness was taken as $\sigma_{a-\mathrm{SiO}_{2}}=0.3 \mathrm{~nm}$, while the $\mathrm{Si}$ wafer substrate roughness was taken as $\sigma_{\text {substrate }}=0.2 \mathrm{~nm}$.) The experimental Bragg peak intensities are best matched for the calculation using $\sigma=0.275 \mathrm{~nm}$, particularly at the largest graze angles where the sensitivity is greatest for reflectance changes resulting from small changes in $\sigma$. By matching the positions and relative intensities of the Bragg peaks, the apparent layer thicknesses were determined to be $d_{W}$ $=2.15 \mathrm{~nm}$ and $d_{\mathrm{Si}}=2.90 \mathrm{~nm}$. Thus the multilayer period $(d)$ and relative volume fraction of $\mathrm{Si}(\Gamma)$ are $d=d_{W}+d_{\mathrm{Si}}$ $=5.05 \mathrm{~nm}$ and $\Gamma=d_{\mathrm{Si}} /\left(d_{W}+d_{\mathrm{Si}}\right)=0.575$, respectively.

Shown in Figs. 5 and 6 are the specular and nonspecular reflectance data for otherwise identical periodic W/Si films containing 100 bilayers, deposited with $P_{\mathrm{Ar}}=2 \mathrm{mTorr}$, but with target-to-substrate distances $D=10.8 \mathrm{~cm}$ (Fig. 5) and $D=11.5 \mathrm{~cm}$ (Fig. 6). From the specular reflectance data [Figs. 5(a) and 6(a)], we estimate comparable periods for the two films $(d=3.925 \mathrm{~nm}$ vs $d=3.750$, with $\Gamma=0.63$ in both cases), but the interface properties are evidently different: the Bragg peak intensities for graze angles greater than $\theta \sim 4^{\circ}$ are markedly smaller for the film deposited with $D$ $=11.5 \mathrm{~cm}$, and we thus infer $\sigma=0.40 \mathrm{~nm}$ for this film versus $\sigma=0.30 \mathrm{~nm}$ for the film having $D=10.8 \mathrm{~cm}$. From the nonspecular data [Figs. 5(b) and 5(c) and 6(b) and 6(c)], which correspond to rocking scans that intersect the second and third Bragg peaks (the ' $2 \theta$ ' values are indicated), we find reasonable agreement with experiment assuming (symmetric $\mathrm{W}$-on-Si and $\mathrm{Si}$-on-W) interface roughness values of $\sigma_{r}$ $=0.175 \mathrm{~nm}$ for the case $D=10.8 \mathrm{~cm}$ vs $\sigma_{r}=0.275 \mathrm{~nm}$ for the case $D=11.5 \mathrm{~cm}$, and with identical values of $\sigma_{d}$ $=0.25 \mathrm{~nm}, \xi_{\|}=0.7 \mathrm{~nm}, H=0.65$, and $\xi_{\perp}=15 \mathrm{~nm}$ for both films. Note that (a) the same interface parameters (i.e., $\sigma_{d}$, $\sigma_{r}, \xi_{\|}, H$, and $\xi_{\perp}$ ) adequately describe both rocking scans in the case of each film, and (b) the interfacial roughness and 

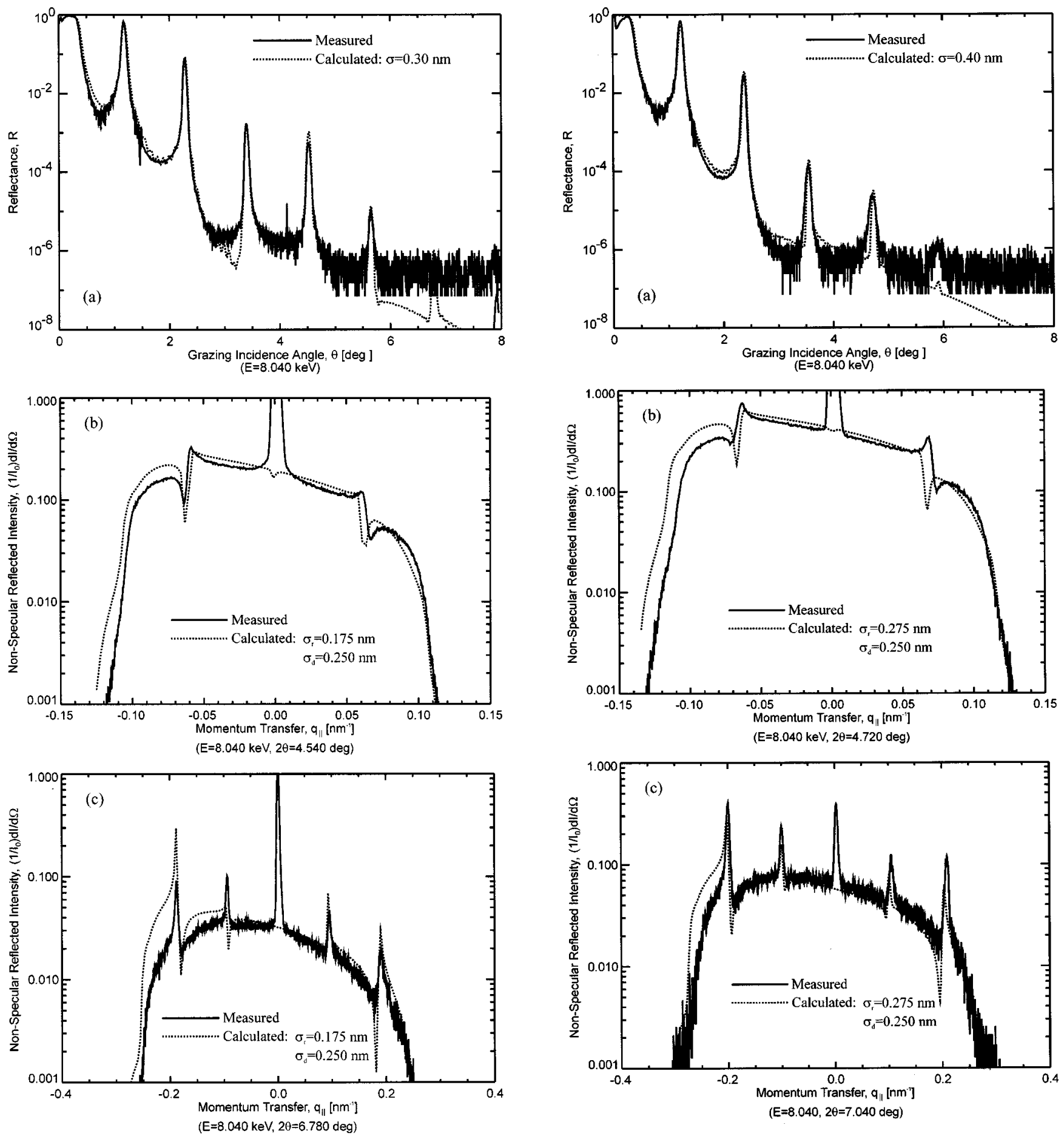

FIG. 5. Specular (a) and nonspecular rocking scans made through the second (b) and third (c) Bragg peaks ( $2 \theta$ values are indicated) for a periodic W/Si multilayer containing 100 bilayers, deposited at $P_{\mathrm{Ar}}=2 \mathrm{mTorr}$, and with a target-to-substrate distance $D=10.8 \mathrm{~cm}$. Calculations made using the parameters discussed in the text are shown for comparison as dotted lines. Note that the footprint of the incident $\mathrm{x}$-ray beam is larger than the sample size for small values of $\theta$, i.e., at the large negative values of $q_{\|}$, which explains why the measured intensity is substantially less than the calculated intensity in these regions. Note also that the calculations do not include the specular beam intensity apparent in the measured curves near $q_{\|}=0$.

diffuseness values inferred from the nonspecular data are consistent with the interface widths determined from specular reflectance, i.e., $\sigma=\sqrt{\sigma_{r}^{2}+\sigma_{d}^{2}}$, for both films. The param-

FIG. 6. Similar to Fig. 5, but for a film deposited with a target-to-substrate distance $D=11.5 \mathrm{~cm}$.

eters determined here for the films shown in Figs. 4-6 do not represent statistically significant fit parameters, but suggest nonetheless that the interfacial roughnesses increase with both increasing argon pressure and with increasing target-tosubstrate distance.

Shown in Fig. 7 are the specular reflectance scans for two nominally identical $\mathrm{W} / \mathrm{Si}$ periodic multilayers containing 20 bilayers, and having a period $d=5.6 \mathrm{~nm}$ (with $\Gamma=0.585$ ), deposited with $P_{\mathrm{Ar}}=1.5 \mathrm{mTorr}$ and $D=11.5 \mathrm{~cm}$, but prepared at different background pressures: by adjusting the pumpdown time in the vacuum system prior to deposition, 


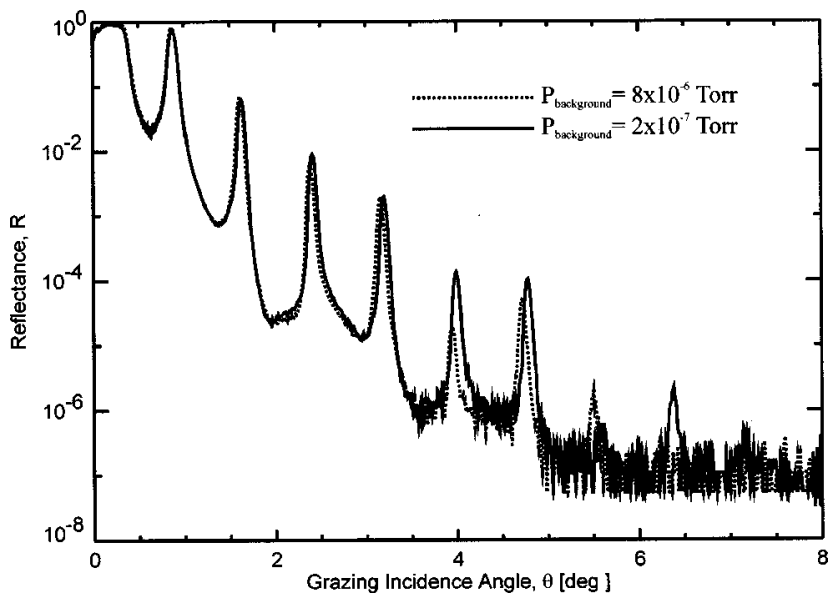

FIG. 7. Specular reflectance measurements for two W/Si multilayers containing 20 bilayers, deposited at two different $P_{\text {background }}$ pressures as indicated.

one sample was prepared with $P_{\text {background }}=2 \times 10^{-7}$ Torr, and the other with $P_{\text {background }}=8 \times 10^{-6}$ Torr. From these data we find that the interface widths increase from $\sigma$ $=0.30$ to $0.35 \mathrm{~nm}$ with increasing $P_{\text {background }}$. Again, the reduction in specular reflectance due to the increased interface widths is most apparent at the largest graze angles (i.e., $\theta>\sim 3.5^{\circ}$ ). The increase in interface widths with increasing background pressure was also observed in other films prepared after various pumpdown times: the widths determined from specular $\mathrm{x}$-ray reflectance measurements consistently increased from $\sigma=0.30$ for films prepared at background pressures less than $\sim 5 \times 10^{-7}$, to $\sigma=0.35 \mathrm{~nm}$ for those prepared at pressures greater than $\sim 2 \times 10^{-6}$ Torr.

In order to deposit depth-graded W/Si multilayers having accurately controlled layer thicknesses, it is necessary to calibrate precisely the $\mathrm{W}$ and $\mathrm{Si}$ deposition rates. We have performed such calibrations by depositing periodic multilayers with bilayer thicknesses spanning the range $d$ $=1.5-30 \mathrm{~nm}$ (corresponding approximately to the range of bilayer thickness needed for astronomical telescopes utilizing depth-graded $\mathrm{x}$-ray multilayers operating over the range $E=20-200 \mathrm{keV}$ ), and using specular x-ray reflectance analysis to determine the apparent $\mathrm{W}$ and $\mathrm{Si}$ layer thicknesses as a function of the $\mathrm{W}$ and $\mathrm{Si}$ deposition times (i.e., the amount of time that the substrate spends over the $\mathrm{W}$ or $\mathrm{Si}$ targets, as determined by the substrate rotation rate). Shown in Figs. 8(a) and 8(b) are plots of apparent layer thickness versus deposition time for $\mathrm{W}$ and $\mathrm{Si}$, respectively, determined for periodic $\mathrm{W} / \mathrm{Si}$ multilayers having relative $\mathrm{W}$ and Si layer thicknesses in the range $\Gamma=0.52-0.68$, deposited at magnetron powers $\left(P_{\mathrm{W}}, P_{\mathrm{Si}}\right)=(300$ and $500 \mathrm{~W})$ and $(600$ and $1000 \mathrm{~W})$. We observe from these data that the apparent layer thicknesses are not linear with deposition time. The thicknesses can be described as a bilinear function of time, however, and such fits to the data are shown in Figs. 8(a) and 8(b). These bilinear fits can be used to predict the measured multilayer periods with an accuracy of better than $0.05 \mathrm{~nm}$, which is sufficient for the deposition of depth-graded multilayers for use as hard x-ray mirrors. We note also that from fits to the specular reflectance data for the periodic multilay-
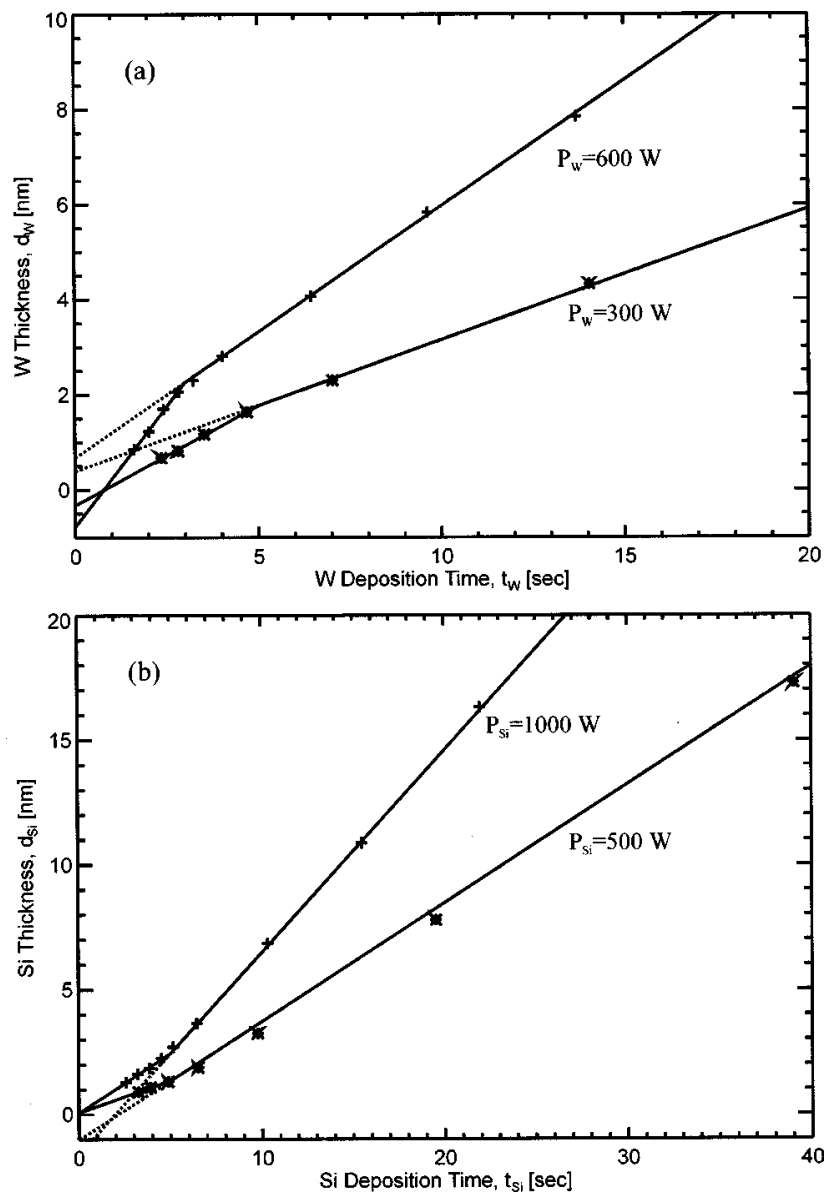

FIG. 8. Layer thickness vs deposition time for W (a) and Si (b) determined from x-ray reflectance analysis of multilayer films deposited at the magnetron powers indicated. Also shown are bilinear fits to these data.

ers used to calibrate the deposition rates we find a slight increase in the interface widths with increasing bilayer thickness: the interface widths increase to $\sigma=0.35 \mathrm{~nm}$ for structures having $d>\sim 20 \mathrm{~nm}$, relative to the interface widths in the range $\sigma=0.275-0.30 \mathrm{~nm}$ determined for structures having smaller bilayer thicknesses. This last result is qualitatively consistent with the increase in $\mathrm{W}-\mathrm{Si}$ interlayer thicknesses observed in TEM [e.g., Figs. 3(a) and 3(b)] and may be due to an increase in interfacial roughness associated with the transition from amorphous to polycrystalline $\mathrm{W}$ layers as observed by TEM and SAED.

For the fabrication of hard $\mathrm{x}$-ray telescopes such as those designed for HEFT and Constellation- $X$ that will require many square meters of coatings, we wish to deposit highquality (i.e., small- $\sigma$ ) films at the highest possible deposition rates in order to minimize the coating time. The deposition rates for sputtered films depend strongly on the power applied to the magnetrons. We have searched, therefore, for any possible change in the interface widths for films deposited at various magnetron powers. We have investigated by $\mathrm{x}$-ray reflectance analysis the interface widths in periodic $\mathrm{W} / \mathrm{Si}$ multilayers deposited at three $\mathrm{W}$ and $\mathrm{Si}$ power settings: $\left(P_{\mathrm{W}}, P_{\mathrm{Si}}\right)=(200$ and $200 \mathrm{~W}),(300$ and $500 \mathrm{~W})$, and $(600$ and $1000 \mathrm{~W})$. We find no systematic variation in the interface widths with magnetron power, and in particular, we are 

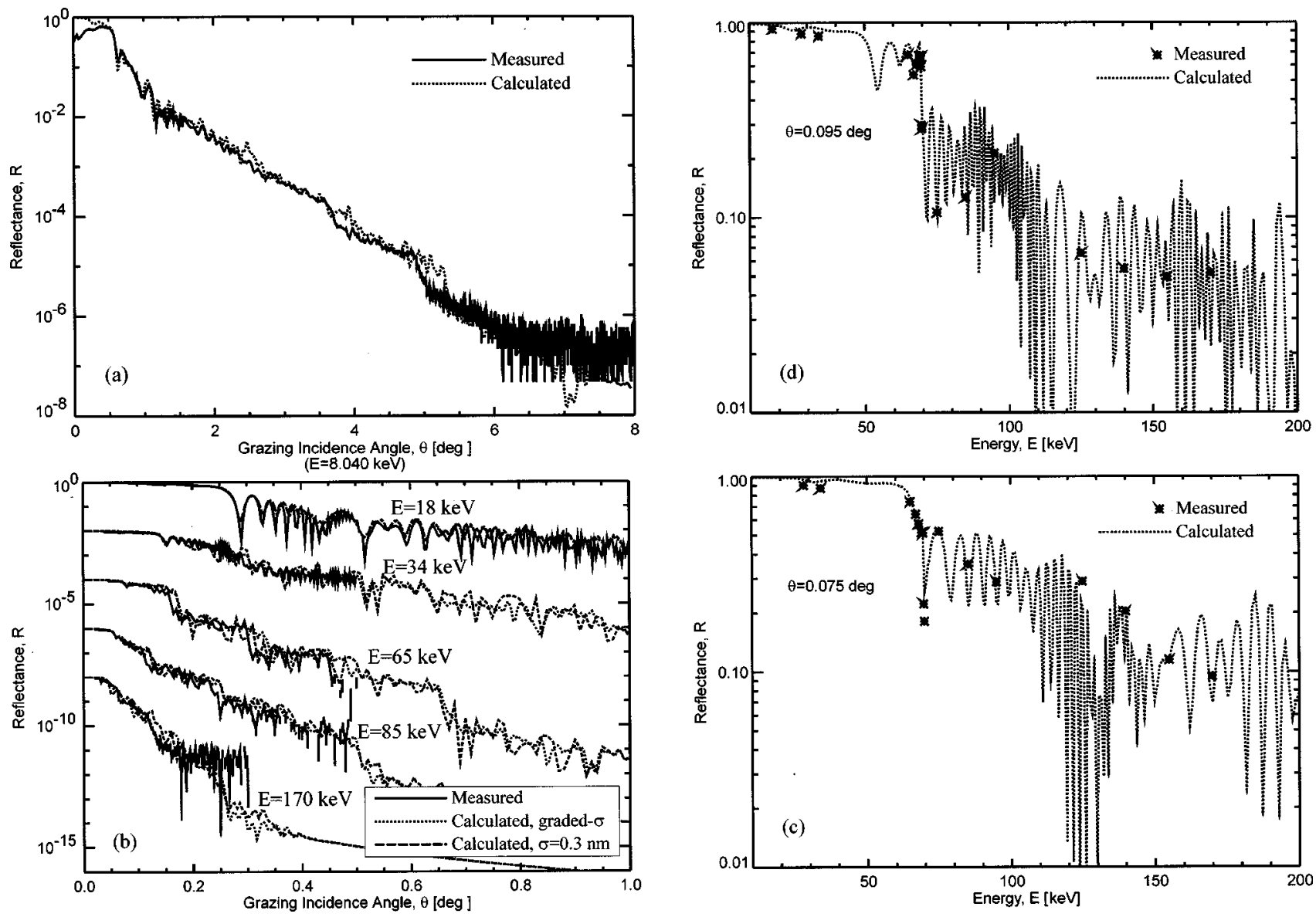

FIG. 9. Specular reflectance for the depth-graded W/Si multilayers. (a) Reflectance vs grazing incidence angle at $E=8.04 \mathrm{keV}$ made using a rotating anode $\mathrm{Cu}$ source. (b) Reflectance vs grazing incidence angle at various energies (as indicated) made using synchrotron radiation. Reflectance vs energy data at $\theta$ $=0.095^{\circ}$ (c) and $0.075^{\circ}$ (d). Shown for comparison in (a) $-(\mathrm{d})$ are calculations made using a depth-graded distribution of interface widths in the range $\sigma$ $=0.275-0.35 \mathrm{~nm}$ [i.e., Eq. (8)]. Also shown in (b) are calculations made using a constant interface width $\sigma=0.3 \mathrm{~nm}$.

able to deposit high-quality films (i.e., those having interface widths in the range $\sigma=0.275-0.35 \mathrm{~nm}$ ) at the highest practical power settings. We note that it is possible to use power settings in excess of $\left(P_{\mathrm{W}}, P_{\mathrm{Si}}\right)=(600$ and $1000 \mathrm{~W})$, but the greater deposition rates that result make it impossible to deposit multilayers having bilayer thicknesses as small as $d$ $\sim 1.5 \mathrm{~nm}$ (with $\Gamma \sim 0.55$ ) given the maximum substrate rotation velocity available in the deposition system used here. Furthermore, high power settings result in greater target erosion rates and consequently larger deposition rate drifts over time; such drifts can be problematic with regard to the production of depth-graded films that have accurately controlled layer thicknesses.

Shown in Fig. 9(a) is the specular reflectance of the depth-graded structure described above and shown in Fig. 2, measured at $E=8.04 \mathrm{keV}$; shown in Fig. 9(b) are measured reflectance versus incidence angle curves of an ostensibly identical structure [i.e., one deposited just after the sample shown in Fig. 9(a) and grown under identical conditions, but on a thicker substrate, as described in Sec. II] measured at ESRF at various energies over the range $18 \mathrm{keV}<E$ $<170 \mathrm{keV}$. Shown for comparison (dotted lines) in Figs. 9(a) and 9(b) are calculations made using (symmetric) interface widths that increase slightly towards the top of the film, as suggested by the TEM and $\mathrm{x}$-ray reflectance results de- scribed above: for the calculations shown in Fig. 9, the interface widths follows a distribution with depth into the film given by

$$
\sigma_{i}=\frac{0.93}{(i+7.66)^{0.225}}, \quad i=1, \ldots, 150
$$

[i.e., with the same exponent as for the bilayer thicknesses given by Eq. (7)], corresponding to interface widths in the range $\sigma=0.275-0.35 \mathrm{~nm} .{ }^{34}$ The agreement is good between the measured and calculated reflectance curves made using this interface width distribution. We note, however, that no significant difference was observed between measurements and calculations made using the interface widths given by Eq. (8) and those made assuming constant interface widths $\sigma \sim 0.3 \mathrm{~nm}$, shown, for example, in Fig. 9(b) as dashed lines. Indeed, quantitative determination of interface parameters drawn from the high-energy synchrotron data is unwarranted in this case, given the relatively low dynamic range of these measurements, and the consequently large experimental uncertainties at the largest graze angles where the reflectance is most sensitive to small changes in $\sigma$.

Shown in Figs. 9(c) and 9(d) are plots of the reflectance versus energy of the same depth-graded film, measured over the range $18 \mathrm{keV}<E<170 \mathrm{keV}$, at grazing incidence angles 


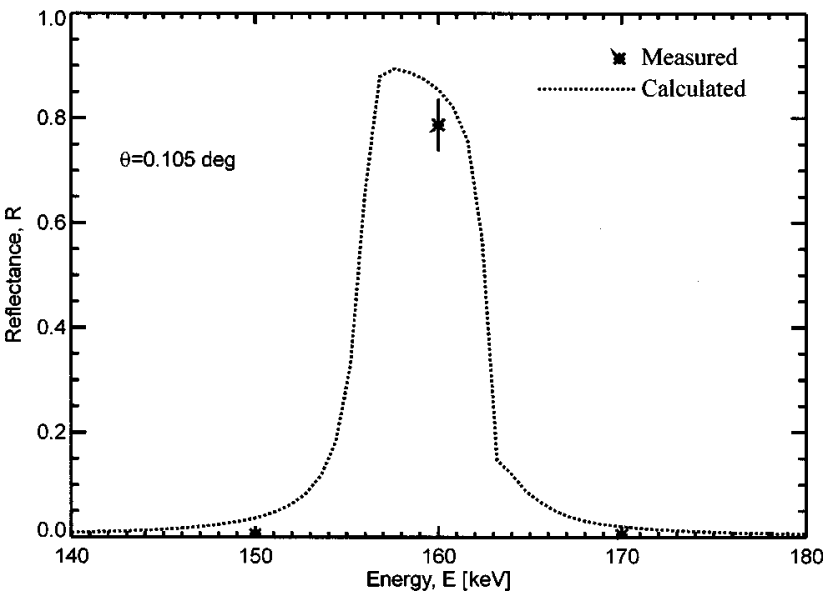

FIG. 10. Measured reflectance vs energy at $\theta=0.105^{\circ}$ for a W/Si multilayer containing 800 bilayers, with bilayer thicknesses in the range $2.09<d$ $<2.25 \mathrm{~nm}$. The calculated reflectance using $\sigma=0.3 \mathrm{~nm}$ interface widths is shown for comparison.

$\theta=0.095^{\circ}$ and $0.075^{\circ}$, respectively; also shown are the calculated reflectance curves, made using the graded interface width distribution just described, which agree favorably with the measurements. ${ }^{35}$ The reflectance of this film drops sharply above the W $K$ edge $(E \sim 69.4 \mathrm{keV})$, where absorption in the film is high; the reflectance at the design incidence angle [i.e., $\theta=0.095^{\circ}$, Fig. 9(c)] is only a few percent for $E>100 \mathrm{keV}$, however at $\theta=0.075^{\circ}$ [Fig. 9(d)] the reflectance is in excess of $10 \%$ up to $E=170 \mathrm{keV}$. Depth-graded coatings identical to those shown in Fig. 9, as well as other coatings designed to operate at smaller graze angles, have been deposited onto the curved glass substrates that will be used for the HEFT hard x-ray telescope, and high energy synchrotron reflectance measurements reveal equivalent performance at the operational graze angles. The hard x-ray performance of the HEFT telescope will be reported in detail elsewhere.

In spite of the large absorption above the $\mathrm{W} K$ edge, W/Si multilayers can still be used effectively for hard X-ray mirrors that operate at energies substantially greater than 100 $\mathrm{keV}$. For example, shown in Fig. 10 is the measured reflectance versus energy (at an incidence angle $\theta=0.105^{\circ}$ ) for a $\mathrm{W} / \mathrm{Si}$ multilayer having a slight gradation in bilayer thickness with depth: this film contains 800 bilayers, with bilayer thicknesses in the range $2.09<d<2.25 \mathrm{~nm}$. The peak reflectance near the center of the Bragg peak (which is only slightly broadened due to the small depth gradation) at $E$ $=160 \mathrm{keV}$ is $R=78.7 \pm 4 \%$, which agrees with the expected reflectance (shown as the dotted line in Fig. 10) within the experimental uncertainty. This same film was also measured at $E=212 \mathrm{keV}$, where the peak reflectance was found to be $R=76.5 \pm 4 \%$ at $\theta=0.08^{\circ}$, again in agreement with the expected value.

\section{DISCUSSION}

The analysis of the specular and nonspecular x-ray reflectance measurements presented above suggests that the dominant interface imperfection in high-quality sputtered $\mathrm{W} / \mathrm{Si}$ multilayer structures is interfacial diffuseness, un- doubtedly corresponding to the amorphous $\mathrm{W}-\mathrm{Si}$ interlayers observed by TEM. These interlayers can form as a result of diffusion during and possibly after film growth, and by mixing resulting from energetic bombardment during growth, as discussed by Hasan et al. ${ }^{11}$ and described above in Sec. II. The slight asymmetry of the W-on-Si vs Si-on-W interlayers observed by TEM (Figs. 2 and 3 ) is further evidence of mixing resulting from energetic bombardment.

The small but nonetheless significant increase in interfacial roughness determined from $\mathrm{x}$-ray reflectance analysis with argon pressure and target-to-substrate distance presented above (Figs. 4 and 5) can also be explained by energetic bombardment. As already mentioned, films deposited by magnetron sputtering can be subjected to a large energy input during growth through collisions with energetic incident adatoms, Ar ions, and reflected neutral Ar atoms. These collisions can drastically affect the film microstructure, stress, and surface roughness through the so-called "atomic peening' ' effect, ${ }^{36}$ and a large number of investigations have been directed at understanding this phenomenon in thin films. ${ }^{37-47}$ As a result of energetic bombardment, polycrystalline metal films prepared at low argon pressure in particular typically consist of tightly packed grains, with highdensity and low surface roughness, i.e., the zone $\mathrm{T}$ microstructure first described by Thornton; ${ }^{38}$ high-density, low roughness amorphous films (i.e., $a-\mathrm{Si}, a-\mathrm{C}$, etc.) can also be produced by low-pressure magnetron sputtering. At high argon pressure, however, as a result of thermalization resulting from collisions in the gas phase, the amount of energy delivered to the surface of the growing film can be much lower. Consequently, in the case of low surface mobility adatoms (e.g., the room-temperature growth of $\mathrm{W}$ on $\mathrm{Si}$ and $\mathrm{Si}$ on $\mathrm{W}$ ), the film roughness can be higher and the density lower due to the large number of voids that can form (i.e., zone 1 microstructure) because of shadowing during growth. ${ }^{48}$

The energetics of the atomic peening process and the effects of thermalization resulting from collisions in the gas phase have been discussed by Somekh, ${ }^{49}$ and later by Windischmann ${ }^{50}$ who suggests that the film microstructure (and stress) is determined chiefly by the normalized momentum $P_{n}^{*}=\gamma(M E)^{1 / 2}$, delivered to the growing film by an energetic particle, where $M$ is the mass, $E$ is the energy, and $\gamma$ is the energetic particle/adatom flux ratio. The particle energy $E$ depends on the product $P_{\mathrm{Ar}} D$ of the argon pressure $P_{\text {Ar }}$ and the target-to-substrate distance $D$ : the distribution of particle momenta will tend towards higher values for small $P_{\mathrm{Ar}} D$ relative to deposition at large $P_{\mathrm{Ar}} D$, conditions which result in greater thermalization. The results presented above showing increased interfacial roughness in periodic $\mathrm{W} / \mathrm{Si}$ multilayers with increasing argon pressure (similar to previously reported results in, e.g., Mo/Si multilayers ${ }^{51}$ ) and increasing target-to-substrate distance are thus consistent with this model of the energetics of the growth process.

The increase in interface widths with increasing background pressure reported above (Fig. 7) can also be explained in terms of the growth energetics. Background pressure has been found previously to have a strong effect on film stress in both periodic $\mathrm{Mo} / \mathrm{Si}$ multilayers ${ }^{52}$ and in $\mathrm{W} / \mathrm{Cr}$ 
bilayer structures, ${ }^{53}$ and this effect can been attributed to a trend from a zone $\mathrm{T}$ towards a zone 1 microstructure resulting from the reduction in surface mobility due to impurity gas atoms $(\mathrm{H}, \mathrm{O}$, etc. $)$ present in the vacuum system during deposition and, more importantly, on the surface of the growing film. As just described, this change in microstructure (and stress) is associated with increased roughness resulting from shadowing during growth. It is possible, therefore, that the observed increase in interface widths with increasing background pressure is due to increased interfacial roughness resulting from an impurity-induced reduction in adatom surface mobility.

The lack of any observed variations in interface width with magnetron power is somewhat surprising in light of the sensitive dependence of microstructure on particle energetics just described, given that higher magnetron powers correspond to larger voltages present between the target and the substrate. Larger voltages would be expected to result in increased energy delivered to the film surface by particle bombardment. However without a detailed molecular dynamics simulation of the sputtering process it is difficult to determine quantitatively how the distribution of particle energies will vary with magnetron voltage for a particular deposition geometry. It is conceivable, therefore, that the large variations in magnetron power investigated here (which correspond to approximately linear voltage changes) produce only small changes in the energy distribution of particles striking the film surface during growth.

Various mechanisms can be invoked to explain the observed nonlinear dependence of layer thickness with deposition time shown in Fig. 8. In particular, diffusion and $\mathrm{W}-\mathrm{Si}$ interlayer formation, as well as the resputtering process discussed in Sec. I, undoubtedly all play some role. However, we have not made any attempt to model the observed behavior quantitatively, given the difficulty in reconciling TEM and X-ray reflectance analysis results used to determine the relative thicknesses of the "pure" $\mathrm{Si}$ and $\mathrm{W}$ layers, and $\mathrm{W}-\mathrm{Si}$ interlayers. Perhaps in the future new models can be developed to describe the x-ray reflectance in which better agreement can be obtained between the model parameters (i.e., layer thicknesses, interface widths, etc.) and those parameters then can be determined accurately from TEM. In any case, the bilinear fits to the observed deposition rates shown in Fig. 8 can be used to predict the measured multilayer periods with high accuracy, as is apparent from the good agreement between the measured and calculated high-energy reflectance data shown in Figs. 9 and 10.

\section{CONCLUSION}

We have used electron microscopy and x-ray scattering to investigate the growth and structure of periodic and depthgraded W/Si multilayer structures prepared by magnetron sputtering under various deposition conditions. From electron microscopy we observe $\alpha$-phase polycrystalline $\mathrm{W}$ in W/Si bilayers thicker than $d \sim 8 \mathrm{~nm}$, but only amorphous (or possibly extremely fine-grained polycrystalline) material in thinner layers. We also observe amorphous $\mathrm{W}-\mathrm{Si}$ interlayers, with a slight asymmetry in the W-on-Si $\left(d_{\mathrm{W}-\mathrm{on}-\mathrm{Si}}\right.$ $\sim 0.8-1.0 \mathrm{~nm}) \quad$ vs $\quad$ Si-on-W $\left(d_{\text {Si-on-W }} \sim 0.6 \mathrm{~nm}\right)$ interfaces. From $x$-ray analysis, we find interface widths in the range $\sigma=0.275-0.35 \mathrm{~nm}$ for multilayer films deposited at low argon pressure, and somewhat larger interface widths (i.e., $\sigma$ $=0.35-0.4 \mathrm{~nm}$ ) for structures grown at higher Ar pressures, higher background pressures, or with larger target-tosubstrate distances.

Apart from the apparent discrepancy between the interface widths inferred from electron microscopy and those determined from specular and nonspecular x-ray reflectance analysis, these measurements suggest that the dominant interface imperfection in these films is interfacial diffuseness; interfacial roughness is minimal in structures prepared under optimal conditions, but can increase for films grown under conditions in which the beneficial effects of energetic bombardment during growth are compromised (e.g., higher argon pressures, etc.), as we have discussed above in detail. (Of course interfacial roughness will be greater for films deposited on rough substrates.)

$\mathrm{X}$-ray reflectance analysis was also used to measure the variation in the $\mathrm{W}$ and $\mathrm{Si}$ deposition rates with bilayer thickness and as a function of magnetron power. We find that the $\mathrm{W}$ and $\mathrm{Si}$ layer thicknesses are nonlinear with deposition time, and we have discussed how diffusion, mixing due to energetic bombardment, and resputtering might explain these results. We have also discussed how bilinear fits to the measured thickness versus time data can be used to predict the measured multilayer periods with accuracy sufficient for the growth of depth-graded structures for use as hard x-ray reflectors. We find no increase in interface width as a function of magnetron power, but we do observe a slight increase in interface width for multilayers having periods greater than $\sim 20 \mathrm{~nm}$. This last result may be due to the transition from amorphous to polycrystalline $\mathrm{W}$ layers observed by TEM and SAED.

The hard $\mathrm{x}$-ray reflectance obtained from an optimized depth-graded $\mathrm{W} / \mathrm{Si}$ multilayer over the range $18 \mathrm{keV}<E$ $<170 \mathrm{keV}$, as shown in Fig. 9, is consistent with the relatively small interface widths determined from $(8 \mathrm{keV}) \mathrm{x}$-ray reflectance analysis, as is evident by the good agreement between measurements and calculations made using either a depth-graded distribution of interface widths in the range $\sigma$ $=0.275-0.3 \mathrm{~nm}$ (i.e., as suggested by $8 \mathrm{keV}$ x-ray analysis), or a constant interface width of $\sigma=0.3 \mathrm{~nm}$ for all interfaces in the stack. The reflectance of this structure at the operational graze angle $\left(\theta=0.095^{\circ}\right)$ is in excess of $50 \%$ over the entire design energy range $20 \mathrm{keV}<E<69.4 \mathrm{keV}$, and is in excess of $10 \%$ up to $E=170 \mathrm{keV}$ at $\theta=0.075^{\circ}$. We also find good agreement between reflectance measurements and calculations made for a graded W/Si structure containing 800 bilayers, designed for use above $100 \mathrm{keV}$, where the peak reflectance at $E=212 \mathrm{keV}$, e.g., was measured to be $R$ $=76.5 \pm 4 \%$ at a graze angle of $\theta=0.08^{\circ}$.

The results presented here showing high reflectance at hard $\mathrm{x}$-ray energies up to $200 \mathrm{keV}$ indicate that depth-graded W/Si multilayer coatings can be used for practical hard x-ray reflectors, and in particular for the new generation of hard $\mathrm{x}$-ray astronomical telescopes currently being developed ${ }^{1-4}$ that are designed to operate at energies below $100 \mathrm{keV}$, and 
possibly for future telescopes designed to operate at energies in excess of $100 \mathrm{keV}$. High quality films can be deposited by (low-pressure) magnetron sputtering, a deposition technique that is easily scaled for large area coatings. We note, in fact, that in order to produce in a reasonable amount of time the many square meters of coated mirrors that will be required for these telescopes, either multiple deposition systems and/or deposition systems using much larger magnetron cathodes likely will be required, since the total deposition times clearly increase linearly with the substrate dimensions. That is, although we find that high-quality films can be produced at high magnetron power settings, the deposition rates cannot be increased indefinitely: as we have discussed, the higher deposition rates that can be obtained at higher powers can result in greater deposition rate drifts, and also make it impossible to deposit multilayers having arbitrarily small bilayer thicknesses given a minimum deposition time per layer, e.g., as determined by the rotational velocity of the substrate, or by whatever other mechanism (e.g., shutters, etc.) might be used to control the deposition time.

\section{ACKNOWLEDGMENTS}

The authors are grateful to E. Ziegler, V. Honkimaki, M. S. Del Rio, A. Souvorov, A. Freund, M. Ohler, and R. Hustache for their help and support in facilitating the highenergy reflectance measurements made at ESRF. This research was supported in part by NASA under Grant No. NAG-5-5128, and by the U.S. Dept. of Energy, Office of Science, Laboratory Technology Division under Contract No. DE-AC05-96OR22464 with Lockheed Martin Energy Research Corp. and Contract No. DE-AC05-76OR00033 with Oak Ridge Associated Universities.

${ }^{1}$ C. J. Hailey, S. Abdali, F. E. Christensen, W. W. Craig, T. R. Decker, F. A. Harrison, and M. Jimenez-Garate, Proc. SPIE 3114, 535 (1997).

${ }^{2}$ K. Yamashita et al., Appl. Opt. 37, 8067 (1998).

${ }^{3}$ Proceedings of the High Throughput X-Ray Spectroscopy Workshop, edited by H. Tananbaum, N. White, and P. Sullivan (Harvard-Smithsonian Center for Astrophysics, Cambridge, MA, 1996).

${ }^{4}$ G. S. Lodha, K. Yamashita, T. Suzuki, K. Tamura, T. Ishigami, S. Takahama, and Y. Namba, Appl. Opt. 33, 5869 (1994).

${ }^{5}$ D. L. Windt, Appl. Phys. Lett. 74, 2890 (1999).

${ }^{6}$ P. Høghøj, E. Ziegler, J. Susini, A. Freund, K. D. Joensen, and P. Gorenstein, Physics of X-Ray Multilayer Structures, Technical Digest Series Vol. 6 (Optical Society of America, Washington, DC, 1994), pp. 142145.

${ }^{7}$ P. H. Mao, F. A. Harrison, Y. Y. Platonov, D. Broadway, B. Degroot, F. E. Christensen, W. W. Craig, and C. J. Hailey, Proc. SPIE 3114, 526 (1997).

${ }^{8}$ D. L. Windt, Proc. SPIE 3448, 280 (1998).

${ }^{9}$ W. C. Shih and W. M. Stobbs, Ultramicroscopy 32, 219 (1990).

${ }^{10}$ As Shih and Stobbs point out, however, due to the finite sample thickness it is not possible from electron microscopy to accurately distinguish between rough and diffuse interfaces.

${ }^{11}$ M. M. Hasan, R. J. Highmore, and R. E. Somekh, Vacuum 43, 55 (1992).

${ }^{12}$ A. K. Petford-Long, M. B. Stearns, C.-H. Chang, S. R. Nutt, D. G. Stearns, N. M. Ceglio, and A. M. Hawryluk, J. Appl. Phys. 61, 1422 (1987).

${ }^{13}$ Z. Jiang, X. Jiang, W. Liu, and Z. Wu, J. Appl. Phys. 65, 196 (1988).
${ }^{14}$ B. A. Vidal and J. C. Marfaing, J. Appl. Phys. 65, 3453 (1989).

${ }^{15}$ P. Ruterana, J. P. Chevalier, and P. Houdy, J. Appl. Phys. 65, 3907 (1989).

${ }^{16}$ P. G. Burkhalter, D. B. Brown, J. V. Gilfrich, J. H. Konnert, P. D'Antonio, H. Rosenstock, L. M. Shirey, M. Thompson, and V. Elings, J. Vac. Sci. Technol. B 9, 845 (1991).

${ }^{17}$ J. B. Kortright, St. Joksch, and E. Ziegler, J. Appl. Phys. 69, 168 (1991).

${ }^{18}$ D. L. Windt, J. Vac. Sci. Technol. A 18, 980 (2000).

${ }^{19}$ T. Salditt, T. H. Metzger, and J. Peisl, Phys. Rev. Lett. 73, 2228 (1994).

${ }^{20}$ T. Salditt, D. Lott, T. H. Metzger, J. Peisl, G. Vignaud, P. Høghøj, O. Schärpf, P. Hinze, and R. Lauer, Phys. Rev. B 54, 5860 (1996).

${ }^{21}$ D. L. Windt and W. K. Waskiewicz, J. Vac. Sci. Technol. B 12, 3826 (1994).

${ }^{22}$ General Optics Inc., 5390 Kazuko Court, Moorpark, CA 93021.

${ }^{23}$ D. L. Windt, Comput. Phys. 12, 360 (1998); the calculations included here were made using IMD Ver. 4.1, available from http:// cletus.phys.columbia.edu/ $\sim$ windt/imd.

${ }^{24}$ D. G. Stearns, J. Appl. Phys. 65, 491 (1989).

${ }^{25}$ L. Nevot and P. Croce, Rev. Phys. Appl. 15, 761 (1980).

${ }^{26}$ D. G. Stearns, D. P. Gaines, D. W. Sweeney, and E. M. Gullikson, J. Appl. Phys. 84, 1003 (1998).

${ }^{27}$ S. K. Sinha, E. B. Sirota, S. Garoff, and H. B. Stanley, Phys. Rev. B 38, 2297 (1988)

${ }^{28}$ V. Holy, J. Kubena, I. Ohlidal, K. Lischka, and W. Plotz, Phys. Rev. B 47, 15896 (1993).

${ }^{29}$ V. Holy and T. Baumbach, Phys. Rev. B 49, 10668 (1994).

${ }^{30}$ D. K. G. de Boer, Phys. Rev. B 53, 6048 (1996).

${ }^{31}$ D. K. G. de Boer, Phys. Rev. B 51, 5297 (1995).

${ }^{32}$ P. H. Mao, F. A. Harrison, D. L. Windt, and F. E. Christensen, Appl. Opt. 38, 4766 (1999)

${ }^{33}$ K. D. Joensen, P. Voutov, A. Szentgyorgyi, J. Roll, P. Gorenstein, P. Hoghoj, and F. E. Christensen, Appl. Opt. 34, 7935 (1995).

${ }^{34}$ The reflectance calculations were made using the atomic scattering factors available from http://www-phys.llnl.gov/V_Div/scattering/asf.html, assuming densities $\rho_{\mathrm{W}}=19.34 \mathrm{~g} / \mathrm{cm}^{3}$ and $\rho_{\mathrm{Si}}=2.2 \mathrm{~g} / \mathrm{cm}^{3}$. These atomic scattering factors do not include corrections due to Compton scattering in the layers, and so the reflectance calculations made at the highest energies $(E>\sim 60 \mathrm{keV}$ ) might be slightly higher than they would otherwise be if Compton-scattering-corrected atomic scattering factors were available.

${ }^{35} \mathrm{We}$ note again, however, that quantitative interface parameters cannot be drawn with high precision from these measurements: even though the signal-to-noise ratio is reasonably high for the data shown in Figs. 9(c) and 9(d), the reflectance is largely insensitive to small changes in $\sigma$ at these small incidence angles, and the data are in fact consistent with interface widths in the range $0.2<\sigma<0.5 \mathrm{~nm}$.

${ }^{36}$ F. M. D'Heurle, Metall. Trans. 1, 725 (1970).

${ }^{37}$ F. A. Doljack and R. W. Hoffman, Thin Solid Films 12, 71 (1972).

${ }^{38}$ J. A. Thornton, J. Vac. Sci. Technol. 11, 666 (1974).

${ }^{39}$ D. W. Hoffman and J. A. Thornton, Thin Solid Films 40, 355 (1977).

${ }^{40}$ J. A. Thornton and D. W. Hoffman, J. Vac. Sci. Technol. 14, 164 (1977).

${ }^{41}$ J. A. Thornton, J. Tabock, and D. W. Hoffman, Thin Solid Films 64, 111 (1979).

${ }^{42}$ C. T. Wu, Thin Solid Films 64, 103 (1979).

${ }^{43}$ P. V. Plunkett, R. M. Johnson, and C. D. Wiseman, Thin Solid Films 64, 121 (1979).

${ }^{44}$ D. W. Hoffman and J. A. Thornton, J. Vac. Sci. Technol. 17, 380 (1980).

${ }^{45}$ D. W. Hoffman, Thin Solid Films 107, 353 (1983).

${ }^{46}$ J. A. Thornton and D. W. Hoffman, J. Vac. Sci. Technol. A 3, 576 (1985).

${ }^{47}$ R. A. Roy and R. Messier, J. Vac. Sci. Technol. A 2, 312 (1984).

${ }^{48}$ G. S. Bales and A. Zangwill, J. Vac. Sci. Technol. A 9, 145 (1991).

${ }^{49}$ R. E. Somekh, J. Vac. Sci. Technol. A 2, 1285 (1984).

${ }^{50}$ H. Windischmann, J. Vac. Sci. Technol. A 9, 2431 (1991).

${ }^{51}$ D. G. Stearns, M. B. Stearns, Y. Cheng, J. H. Stith, and N. M. Ceglio, J. Appl. Phys. 67, 2415 (1990).

${ }^{52}$ D. L. Windt, W. L. Brown, C. A. Volkert, and W. K. Waskiewicz, J. Appl. Phys. 78, 2423 (1995).

${ }^{53}$ D. L. Windt, J. Vac. Sci. Technol. B 17, 1385 (1999). 